\title{
Research on the Development Path of Kindergarten-based Curriculum With Liangshan Yi Culture
}

\author{
Lijuan Xiong, Hongye Geng
}

School of Education and Psychological Science, Sichuan University of Science \& Engineering, Zigong 643000, Sichuan, China. Fund Project: Southern Sichuan Preschool Aesthetic Education Development Research Center, Zigong City Philosophy and Social Science Key Research Base, 2020, (XQMY20-04)

Abstract: As the tradition and wisdom of Yi people, Liangshan Yi culture is an important resource for kindergartens in Liangshan Yi area to develop curriculum. This article analyzes the educational value and development principles of Liangshan Yi culture integrated into kindergarten curriculum, and proposes a kindergarten curriculum development path that integrates Liangshan Yi culture from five aspects: theme activities, regional activities, environmental creation, life activities, and resources outside the kindergarten.

Keywords: Liangshan Yi Culture; Kindergarten-based Curriculum; Development Path

\section{Introduction}

Considering characteristics and laws of the physical and mental development of children, the concept of "kindergarten-based curriculum" transplanted from "school-based curriculum" is based on the principal of the kindergarten who can fully mobilize the participation of all parties to integrate various resources inside and outside the kindergarten, guided by the national education goal and based on the reality of the kindergarten, in order to form a curriculum system and form suitable for the actual development of children in this kindergarten ${ }^{[1]}$. The Guidelines for Kindergarten Education (Trial) pays great attention to the development and utilization of kindergarten curriculum resources, especially the development of local kindergarten curriculum. It points out in its educational content and requirements that all kinds of urban and rural kindergartens should make full use of various local educational resources to construct courses suitable for the development of local children; the kindergarten education content should focus on the actual and real life of children; minority areas should also help children learn their own national language ${ }^{[2]}$. From this point of view, in ethnic minority areas, kindergartens should integrate local ethnic culture into kindergarten-based curriculum, in doing so, understanding, respect, and equality can be inculcated in the children by perceiving the diversity and differences of human culture, which is in line with the Guideline.

Located in the southwestern part of Sichuan Province, Liangshan Yi Autonomous Prefecture is China's largest Yi ethnic community with the largest ethnic group and minority population in Sichuan. Covering an area of 60, 400 square kilometers, the prefecture has jurisdiction over 17 counties and cities (6 counties and cities in the Anning River Valley area where Han and ethnic minorities live together, 10 counties in the Daliangshan area where Yi people live, and Muli County which is one of the Tibetan autonomous counties in the country) with a total population of 5, 299, 400, of which the Yi population accounts

Copyright(C 2020 Lijuan Xiong et al.

doi: 10.18686/ahe.v4i10.2928

This is an open-access article distributed under the terms of the Creative Commons Attribution Non-Commercial License (http://creativecommons. org/licenses/by-nc/4.0/), which permits unrestricted non-commercial use, distribution, and reproduction in any medium, provided the original work is properly cited. 
for $53.62 \%{ }^{[3]}$. The development of kindergartens with Yi culture in Liangshan Yi ethnic area not only conforms to the current trend of advocating diversified education, but also reflects the country's policy orientation of attaching importance to preschool education in ethnic areas. Incorporating Liangshan Yi culture into the kindergarten curriculum development path can diversify the kindergarten's educational resources, form a unique kindergarten curriculum, and enrich the content of the kindergarten curriculum.

\section{The educational value}

\subsection{Enhance children's sense of national identity and pride; inherit and develop Yi's culture}

In today's economic globalization and cultural diversification, exchanges and cooperation between different countries, nations, and regions are becoming more frequent. The rapid development of information technology has accelerated the dissemination of various cultures. The inheritance and development of national culture has been unprecedentedly challenged. In the Liangshan Yi area, some traditional folk customs and national culture are gradually declining. For example, most Yi children currently hardly understand the Yi language; except for weddings, funerals and traditional festivals, Yi children rarely wear traditional costumes that symbolize national culture; the Bimo culture, the soul of Yi culture, has passed away with the old generations. National culture needs to be inherited from generation to generation. If Yi culture wants to develop and innovate, it must pay attention to the influence of education on cultural inheritance. Incorporating Liangshan Yi culture into the kindergarten environment creation, cultural construction, and activity development, so that children can understand and familiarize themselves with the history of their own national culture, which is conducive to forming children's sense of belonging and love for their own national history and culture, thus enhancing their national self-confidence.

\subsection{Diversify and enrich educational resources in kindergartens}

The development and utilization of multiple educational resources is the core link of kindergarten curriculum. The content of Liangshan Yi culture involves life, etiquette, cultural heritage, crafts and technology, festival celebrations and other aspects. As part of a country with 56 ethnic groups and an area where multiple cultures coexist harmoniously, education needs to be more diversified. Inheriting our national culture can not only improve the scientific, cultural, ideological and moral quality of the whole nation, but also promote national cohesion and cultural soft power, making social and cultural life more colorful ${ }^{[4]}$. From this perspective, incorporating Liangshan Yi culture into kindergarten curriculum can offer local children access to multiple cultures, broaden national cultural horizon, and improve cultural awareness and judgment.

\section{The principles}

\subsection{The principle of life}

An outstanding feature of national culture is life, because traditional national culture is formed and developed in a specific natural and human environment ${ }^{[5]}$. Life is one of the important characteristics of the kindergarten curriculum that distinguishes it from the primary school curriculum. The development of kindergarten-based curriculum integrated with Liangshan Yi culture should follow the principle of life, and meet the actual needs of the physical and mental development and learning characteristics of preschool children. Without the real life of Liangshan Yi culture, education can only stay on a superficial level, which will make it difficult for the Yi people of Liangshan to understand the essence of Yi culture. Therefore, taking children's life experience as the content carrier, and use real experience as the activity method, the curriculum should be full of life content. This principle could be described as " from children's real life, to children's real life".

\subsection{The principle of nationality}

Reflecting regional and ethnic characteristics are the basic prerequisites for the development of kindergarten-based curriculum in minority areas. As an important imprint of a national culture in a minority area, the ethnicity embodies the inherent way of life in a region, which is the cultural content passed down from generation to generation by the people of all ethnic groups ${ }^{[6]}$. Therefore, only by understanding the life background of Yi children can educators understand the 
children's language and behavior, and adopt scientific and reasonable educational methods and strategies. The development of kindergarten-based curriculum integrated with Yi culture must adhere to the principle of ethnicity, based on the nature, culture and society of the Yi ethnic area in Liangshan, by combining the cognition, language and behavior characteristics of Yi children, to make formulate curriculum goals, content and teaching methods suitable with the cultural characteristics. In doing so, we can deepen children's understanding of their own living environment, and develop their emotional competence for the local ethnic group.

\subsection{The principle of integrity}

The integrity of kindergarten curriculum development is the need of children's physical and mental development and an objective requirement of the kindergarten education. Integrity requires the use of organically integrated educational methods to unify the educational content, so as to give play to the comprehensive functions of the kindergarten curriculum and achieve the goal of overall harmonious development of learners ${ }^{[7]}$. The integration of the characteristic resources of ethnic minority with the five major educational activities of kindergartens is a concrete manifestation of the principle of integrity. Take the Yi nationality torch festival education activity as an example, when children participant in it, they can understand the nutritional composition of festive food and develop good eating habits; when children learn to compile holiday particles and chant ethnic nursery rhymes, they can make progress in the language field; when children learn festival costume patterns and traditional tiedyeing techniques, they can know more scientific knowledge; when children experience the folk customs of the torch festival and visit relatives in the mountains, they can cherish family ties; when they learn to make festival torches, sing and dance, arts education could be done by this way.

\section{The specific path}

\subsection{Integrating Yi culture into theme activities}

Thematic activity is to organize education and teaching activities around a certain central content close to the life of children, which needs to determine the basic clues for the theme development according to the core content, and then follow the basic clues to determine the specific content ${ }^{[8]}$. The theme activities integrated into Yi culture help children have a deeper understanding and experience of Liangshan Yi culture.

The "Outline" mentioned that the content of preschool education should reflect the "comprehensiveness", "enlightenment" and the "interpenetration" among various educational fields, and integrate the contents of the five major fields of health, science, society, language and art in thematic activities. Carrying out kindergarten theme activities around Liangshan Yi nationality's unique traditional customs, culture, festivals, etc., in a comprehensive and systematic interaction with children, it can broaden the use of Yi cultural courses, expand children's vision and knowledge experience, and reflect the three principles of life, nationality and integrity.

Tables 1, 2, and 3 are examples of thematic activities in the five fields:

Table 1. theme activities of upper kindergarten: Happy Yi year (Ku Si)

\begin{tabular}{|c|l|}
\hline Field & \multicolumn{1}{|c|}{ Activity Content } \\
\hline Health & $\begin{array}{l}\text { Sports Activities: Stomping Jump, Torch Passing, Cock Fighting } \\
\text { Healthy Diets: Tuo Tuo Meat }\end{array}$ \\
\hline Science & History of Yi People, The Growth of Potatoes \\
\hline Society & Visiting Relatives, Round Dining Table in Yi Family, Happy Harvest \\
\hline Language & $\begin{array}{l}\text { Poetry and Nursery Rhymes: Golden Liangshan Mountains, A City Where Spring Dwells } \\
\text { Story of Yi Nationality: Yihai Alliance, Zhige Alu Conquering Python }\end{array}$ \\
\hline Art & $\begin{array}{l}\text { Music activities: dance: Happy Nuosu; song: Toast Song; appreciate: Amore Niunie } \\
\text { Art activities: drawing: My Floral Skirt; handwork: Handsome Chaval; appreciate: Architecture of Yi } \\
\text { People }\end{array}$ \\
\hline
\end{tabular}


Table 2. theme activities of lower kindergarten: Yizhou is my hometown

\begin{tabular}{|c|l|}
\hline Field & \multicolumn{1}{c|}{ Activity Content } \\
\hline Health & $\begin{array}{l}\text { Sports activities: Wrestling, Tigers Protecting Its Cubs, Haunting in Mountains } \\
\text { Healthy Diets: Buckwheat Ba Ba }\end{array}$ \\
\hline Science & Understanding Soma Flower, Making Round Root Vegetables \\
\hline Society & Our Year of the Yi Nationality, The Belief in Fire \\
\hline Language & $\begin{array}{l}\text { Poetry Nursery Rhymes: Zmogni, Zuanshan Ballad } \\
\text { Yi Nationality Story: The Legend of Hulusheng }\end{array}$ \\
\hline Art & $\begin{array}{l}\text { Music activities: dance Datty Dance, song A xi Lixi; appreciate: Ajru } \\
\text { Art activities: drawing: I love my hometown, handwork: Dyeing Fabric, appreciate: Embroidering Purse }\end{array}$ \\
\hline
\end{tabular}

Table 3. theme activities of nursery: Happy babies of Yi people

\begin{tabular}{|c|l|}
\hline Field & \multicolumn{1}{|c|}{ Activity Content } \\
\hline Health & $\begin{array}{l}\text { Sports activities: Picking Mushroom, Passing Potatoes, Rotating Umbrella } \\
\text { Healthy Diets: Pickled Chinese Cabbages And Potatoes Soup }\end{array}$ \\
\hline Science & My Tile House \\
\hline Society & Yi People Etiquette, My Clothes Is Different From Others \\
\hline Language & $\begin{array}{l}\text { Poetry and Nursery Rhymes: The Big Cart, Ashima } \\
\text { Yi Nationality Story: The Moon's Daughter }\end{array}$ \\
\hline Art & $\begin{array}{l}\text { Music Activities: dance: Doloho, song: Aiasi, appreciate: A Si Niu Niu } \\
\text { Art Activities: drawing: Collision of Black, Red, and Yellow, handwork: Making Bracelets, appreciate: } \\
\text { Lacquer Wares of Yi People }\end{array}$ \\
\hline
\end{tabular}

\subsection{Adding Yi culture to regional activities}

Regional activities in kindergarten are flexible, so they could be an important part of the process of integrating Yi culture with kindergarten-based curriculum. The types of art and forms of activities in Liangshan Yi culture that are suitable for setting up regional activity places could be selected to help local children learn Yi culture. For example, in the construction area, a variety of Yi architectural works could be displayed, in doing so, based on existing experience, children can use wooden blocks, cartons, branches, newspapers, ropes and other materials to build their own tiled houses of Yi family through observation and imagination, which is a good way to soak up the history and architecture of the Yi culture; in the art work area, teachers could guide children to observe the unique colors, patterns and laces of Yi costumes or Yi lacquerware, and put suitable materials such as cloth, paper-cutting, colored rope, paint, light clay and other materials in characteristic art and handicraft courses, allowing children to enjoy the aesthetic appeal understand their own national culture; in the puzzle area, inspired by the unique folk stone game of Liangshan Yi culture, teachers could lead children to draw a four-vertical and five-horizontal chessboard on a slate or a cardboard, and use stones, wooden blocks, grass knots and other materials as chess pieces of different styles, so that children can be trained minds in the game of stone chess with Yi culture; in the performance area, teachers could put in folk costumes such as Chaerva, pleated long skirts, floral waistbands, blouses with big breasts, cockscomb hats, swallow hats, and folk musical instruments such as Yue Qin, mouth chords, Hulu Sheng, Ma Bu, so that children can wear Yi costumes and hold Yi musical instruments in hand. In this environment, children can use imagination to create and perform in the musical melody full of Yi nationality characteristics, which aims to enrich their musical appreciation; in the reading area, preschools could provide books of Yi fairy tales, nursery rhymes, folk legends to encourage children to confidently create and tell stories, which not only exercises their language expression and communicative skills, but also inculcates students with the love of traditional culture of the nation.

\subsection{Permeating Yi culture in environmental creation}

According to the Kindergarten Work Regulations, we need to create a good environment suitable for education to provide 
children with opportunities and conditions for activities and performance, which aims at promoting different development of each child on the original level ${ }^{[9]}$. Based on the children's physical and mental development characteristics and existing life experience, the kindergarten teachers need to make full use of the educational value created by the environment and integrate the characteristic cultural elements of the Yi ethnic group in Liangshan, so that children can be influenced, suggested and infected by the Yi ethnic culture unknowingly, which helps to inherit the precious culture through cultural environment.

Table 4. liangshan Yi people's cultural contents

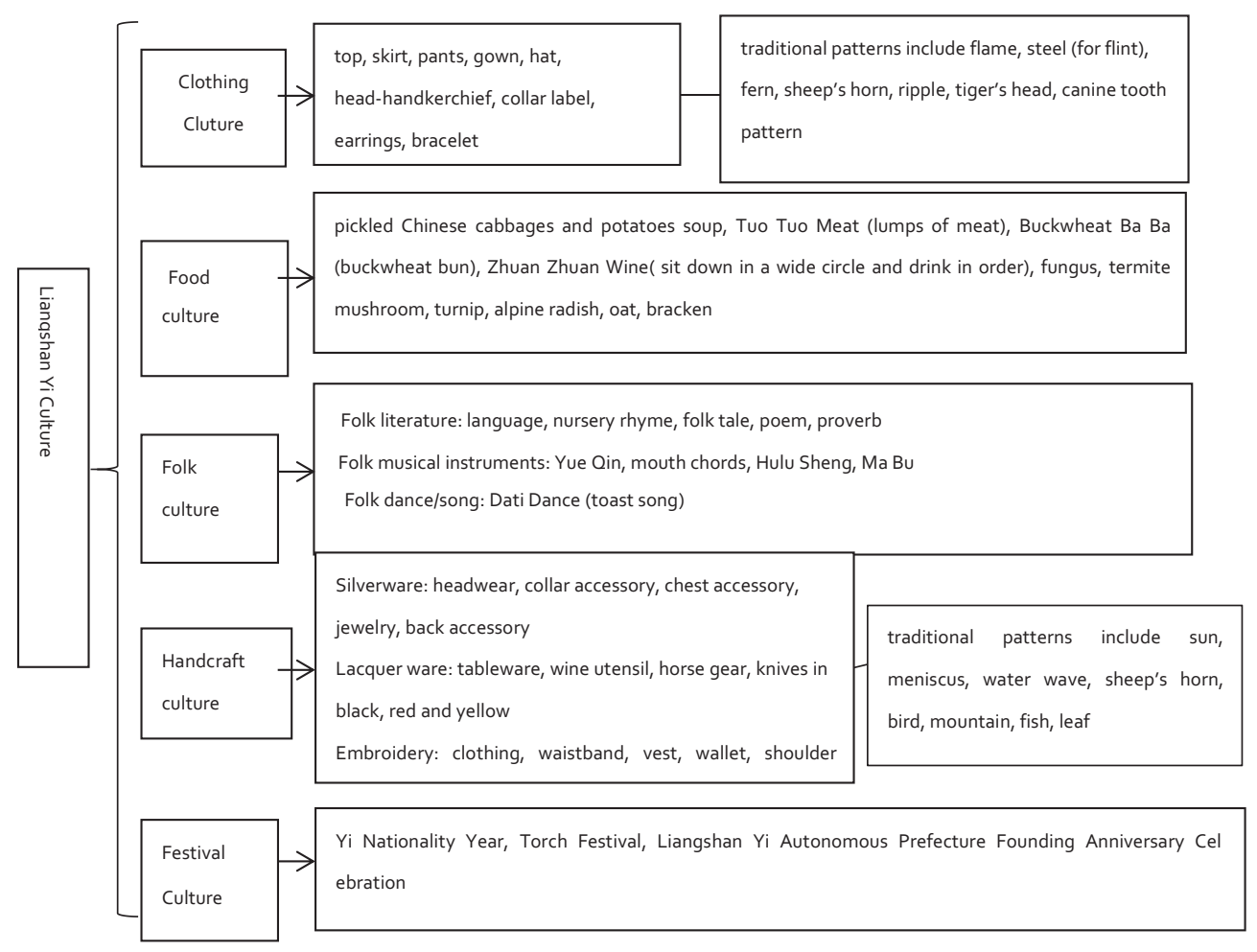

According to Table 4, it can be seen that the Yi culture is rich and diverse, which offers enough elements with national characteristics to the creation of the kindergarten environment. For example, the red, black, and yellow colors commonly used in daily life of the Yi people could be the main colors of the kindergarten; special patterns or simple characters in the Yi people's clothing, appliances, and buildings can be used for the wall or corridor decoration; the yellow umbrella of Dole he, Yi girls' must-use in festival ceremonies, can be used to decorate the ceiling of the kindergarten corridor or hall. Using Liangshan Yi culture to decorate the kindergarten not only reflects the educational value of the environment, but also promotes the enthusiasm of children to learn Yi culture.

\subsection{Combing Yi culture with daily activities}

As cultivated activities, the daily activities in the kindergarten consist of eating, sleeping, washing hands, going to the toilet, entering and leaving the kindergarten, and cleaning ${ }^{[10]}$. The learning and inheritance of Liangshan Yi culture can penetrate into the daily activities. For example, when children enter the kindergarten in the morning and leave the kindergarten in the afternoon, the kindergarten's broadcast can play relaxed and cheerful Yi rhymes; when children wake up from a nap, these preschools can play the light music played by Liangshan Yi's mouth chords, Hulu Sheng, Yue Qin and other musical instruments; when children are doing morning exercises, the rhythm of Dati Dance of Yi culture can be integrated into the movement, fully showing the localized and diversified characteristics of the kindergarten's morning exercise arrangements; during lunch, the Liangshan Yi food could be added to the kindergarten catering, and the teacher can explain the food characteristics, eating methods and function, in addition, the tableware for the meal can use the special lacquerware made by the Yi people in black, red and yellow; before the meal and before the nap, the teacher can tell the children some Yi folk stories and traditional customs of the Yi people. This subtle way of interspersing Yi culture in daily activities makes Yi cultural education more life-oriented and more suitable for children's learning characteristics. 


\subsection{Discovering Yi culture in resources outside the kindergarten}

The development of kindergarten-based curriculum that integrates Yi culture can explore the Yi cultural and educational resources outside the kindergarten such as family, community and Internet to make up for the lack of curriculum resources in the kindergarten and better improve the construction of kindergarten-based curriculum. As an important partner of the kindergarten, the role of the family cannot be ignored in the development of the kindergarten-based curriculum that integrates the Liangshan Yi culture. For example, we need to encourage parents to teach Yi culture at home, infiltrate Yi culture in the family environment, and innovate Yi culture by cooperation with kindergartens. The second is the use of community resources. Ethnic museums, folk custom museums, libraries, exhibition halls are all community educational resources that can be developed and utilized. The Yi people's stories, children's songs and rhymes, ethnic pictorials are all valuable gardenbased curriculum materials and of great educational value. The third is Internet resources. In a era of rapid development of information technology, Internet official accounts, Weibo, WeChat, and QQ groups can all be used as platforms for interconnection and sharing of educational activities. In the vast Internet space, children can more fully perceive the harmony and difference of world culture and national culture, which could enhance their love for their own nation and recognition of Yi culture.

\section{References}

1. Li PR. Research on the construction of kindergarten-based curriculum from the perspective of local culture. China West Normal University; 2018.

2. Department of basic education, ministry of education. Guidelines for Kindergarten Education (Trial). Nanjing: Jiangsu Publishing House; 2007.

3. Liangshan Yizhou News Net. Introduction to Liangshan Yi autonomous prefecture 2019; 3.6. http://www.lszxc.cn/ html/2019/lsxw_0827/12589.html

4. Luo WY. Research on the development and utilization of Yi cultural curriculum resources in kindergartens in Yi ethnic areas. Sichuan Normal University; 2019.

5. Wu HD. Research on the basic principles and paths of kindergarten development in ethnic areas. Journal of Lanzhou Institute of Education 2019; 35(08): 173-174.

6. Kong L. My opinion on the status and role of intangible cultural heritage protection and inheritance in mass cultural activities. Popular Literature and Art 2019; (18): 16-17.

7. Zhejiang Preschool Education Network. About the development of kindergarten curriculum 2019; 3.21. http://data.06abc. com/20120620/16639. html

8. Wang XH. Integrating regions and topics to promote children's all-round development. Elementary School Science (Teacher Edition)2015; 5.

9. Liu ZL. Authoritative interpretation of the new rules of kindergarten work 2016; 3.22. http://www.yi-tong.com/news_sub/ items/1911_1005html

10. Zhu JX. Design and implementation of kindergarten education activities. Beijing: Higher Education Press; $2008: 228$. 